\title{
Long-term post-trial follow-up of participants in randomised trials: lessons learned from the mrc / bhf heart protection study (HPS)
}

\author{
Theingi Aung ${ }^{*}$, Richard Bulbulia, Louise Bowman, Jane Armitage \\ From 2nd Clinical Trials Methodology Conference: Methodology Matters \\ Edinburgh, UK. 18-19 November 2013
}

\section{Introduction}

Treatment effects may be significantly underestimated by analyses restricted to the relatively brief intervention phase of a randomised trial, and effects on cancer may only emerge during prolonged follow-up. In HPS, posttrial follow-up for non-fatal events was largely achieved via annual postal questionnaires, and the methods used may help inform the design of subsequent similar studies.

\section{Methods}

20,536 patients at increased vascular risk were randomly allocated $40 \mathrm{mg}$ simvastatin or placebo for a mean "in-trial" duration of 5.3 years. Post-trial follow-up of all 17,519 surviving participants yielded a mean total follow-up of 11.0 years, with non-fatal events and statin use reported by participants in annual mailed questionnaires or via GPs, supplemented with cause-specific mortality and site-specific cancer incidence via central registries.

\section{Results}

Response rates to annual postal questionnaires were around $80 \%$ each year and total 34,555 non-fatal events were reported. Number of events reported from different sources showed: 24,691 from questionnaire, 6162 from cancer registries, 3400 via GPs, 239 from letters/phone calls and 63 from non-fatal events on death certificate. Based on these large numbers of fatal and non-fatal events, long-term follow-up of HPS reliably demonstrates the long-term efficacy and safety of lipid-lowering statin therapy.

Clinical Trial Service Unit (CTSU), University of Oxford, Oxford, UK

\section{Conclusion}

Capturing non-fatal post-trial events via postal questionnaires is effective, and allows reliable assessment of the benefits and potential hazards of the intervention being studied. However, the process was labour-intensive, and follow-up via Hospital Episode Statistics (HES) data may be an alternative cost effective means of comprehensively gathering such data in future studies.

Published: 29 November 2013

doi:10.1186/1745-6215-14-S1-084

Cite this article as: Aung et al:: Long-term post-trial follow-up of participants in randomised trials: lessons learned from the mrc / bhf heart protection study (HPS). Trials 2013 14(Suppl 1):O84.
Submit your next manuscript to BioMed Central and take full advantage of:

- Convenient online submission

- Thorough peer review

- No space constraints or color figure charges

- Immediate publication on acceptance

- Inclusion in PubMed, CAS, Scopus and Google Scholar

- Research which is freely available for redistribution

\section{() Biomed Central}

\section{()

